\title{
Tumor mutation burden and circulating tumor DNA in combined CTLA-4 and PD-1 antibody therapy in metastatic melanoma - results of a prospective biomarker study
}

Andrea Forschner ${ }^{1 *}$ D , Florian Battke ${ }^{2}$, Dirk Hadaschik², Martin Schulze ${ }^{3}$, Stephanie Weißgraeber ${ }^{2}$, Chung-Ting Han², Maria Kopp², Maximilian Frick², Bernhard Klumpp ${ }^{4}$, Nicola Tietze ${ }^{5}$, Teresa Amaral ${ }^{1,6}$, Peter Martus ${ }^{7}$,

Tobias Sinnberg' ${ }^{1}$, Thomas Eigentler', Ulrike Keim', Claus Garbe', Dennis Döcker ${ }^{2,3+}$ and Saskia Biskup ${ }^{2,3+}$

\begin{abstract}
Background: Metastasized or unresectable melanoma has been the first malignant tumor to be successfully treated with checkpoint inhibitors. Nevertheless, about $40-50 \%$ of the patients do not respond to these treatments and severe side effects are observed in up to $60 \%$. Therefore, there is a high need to identify reliable biomarkers predicting response.

Tumor Mutation Burden (TMB) is a debated predictor for response to checkpoint inhibitors and early measurement of ctDNA can help to detect treatment failure to immunotherapy in selected melanoma patients. However, it has not yet been clarified how TMB and ctDNA can be used to estimate response to combined CTLA-4 and PD-1 antibody therapy in metastatic melanoma.
\end{abstract}

Patients and methods: In this prospective biomarker study, we included 35 melanoma patients with ipilimumab (anti-CTLA-4) and nivolumab (anti-PD-1) therapy. In all patients, a tumor panel of 710 tumor-associated genes was applied (tumor vs. reference tissue comparison), followed by repetitive liquid biopsies. Cell-free DNA was extracted and at least one driver mutation was monitored. Treatment response was evaluated after about three months of therapy.

Results: TMB was significantly higher in responders than in nonresponders and TMB > 23.1 Mut/Mb (TMB-high) was associated with a survival benefit compared to TMB $\leq 23.1$ Mut/Mb (TMB-low or TMB-intermediate). Furthermore, a $>50 \%$ decrease of cell-free DNA concentration or undetectable circulating tumor DNA (ctDNA), measured by tumor-specific variant copies/ml of plasma at first follow-up three weeks after treatment initiation were significantly associated with response to combined immunotherapy and improved overall survival, respectively. It is noticeable that no patient with $\mathrm{TMB} \leq 23.1 \mathrm{Mut} / \mathrm{Mb}$ and detectable or increasing ctDNA at first follow-up responded to immunotherapy.

Conclusion: High $\mathrm{TMB}_{1}>50 \%$ decrease of cell-free DNA concentration, and undetectable ctDNA at first follow-up seem to be associated with response and overall survival under combined immunotherapy. The evaluation of ctDNA and cell-free DNA three weeks after treatment initiation may be suitable for early assessment of efficacy of immunotherapy.

\footnotetext{
* Correspondence: andrea.forschner@med.uni-tuebingen.de

${ }^{\dagger}$ Dennis Döcker and Saskia Biskup contributed equally.

${ }^{1}$ Center for Dermatooncology, Department of Dermatology, University

Hospital Tuebingen, Liebermeisterstr. 25, 72076 Tuebingen, Germany

Full list of author information is available at the end of the article
}

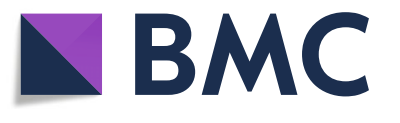

(c) The Author(s). 2019 Open Access This article is distributed under the terms of the Creative Commons Attribution 4.0 International License (http://creativecommons.org/licenses/by/4.0/), which permits unrestricted use, distribution, and reproduction in any medium, provided you give appropriate credit to the original author(s) and the source, provide a link to the Creative Commons license, and indicate if changes were made. The Creative Commons Public Domain Dedication waiver (http://creativecommons.org/publicdomain/zero/1.0/) applies to the data made available in this article, unless otherwise stated. 


\section{Introduction}

Checkpoint inhibitors such as pembrolizumab, nivolumab, or combination of ipilimumab and nivolumab have significantly improved prognosis of patients with metastatic melanoma. Nevertheless, about $40-50 \%$ of the patients do not respond to these treatments and severe side effects such as immune-mediated colitis, hepatitis, pneumonitis, or endocrinological diseases are observed in up to $60 \%$ [1-4]. Therefore, there is a high need to identify reliable biomarkers predicting response. Programmed cell death ligand 1 (PD-L1) expression on the tumor cell surface was shown not to be a reliable predictive biomarker for response or survival as checkpoint inhibitors also are effective in patients with PD-L1 negative tumors [5-7]. Furthermore, PD-L1 expression was shown to be inconsistent between primary tumors and metastases and even between metastases within one patient in about $50 \%$ of the cases [8]. Among patients treated with pembrolizumab, presence of liver metastases at treatment initiation was found to be associated with significant reduced response rates and progressionfree survival, possibly due to reduced $\mathrm{CD}^{+}$T-cell infiltration at invasive margins $[9,10]$. Cutaneous melanoma is a tumor that exhibits a rather high tumor mutation burden (TMB) [11], although there is a very high variation and by far not all melanomas are TMB-high. The correlation between high TMB and response to immunotherapy is not completely clarified but it is potentially a predictor for response [12-18]. It is unclear whether there is an individual TMB cut-off for each type of tumor [19]. So far, there are no precise data on the influence of TMB in melanoma patients with combined immunotherapy on therapy response and survival.

In recent months, there were new insights in the use of circulating tumor DNA (ctDNA) as a predictive marker for early response and prognosis for melanoma patients with checkpoint inhibitors. Patients with persistently elevated ctDNA levels early on treatment had a poor prognosis [20, 21]. Furthermore, increase of ctDNA was found being highly predictive of progressive disease in melanoma patients with BRAF or NRAS mutations [22].

In this prospective study we performed a comprehensive panel sequencing approach using tumor versus normal tissue and repeated liquid biopsies of patients that newly started a combined ipilimumab and nivolumab therapy for metastasized melanoma. The tumor panel comprised 710 tumor-associated genes covering $>2 \mathrm{Mb}$ to reliably calculate TMB [23] to detect all known driver and resistance mutations including copy number variation. Additionally, at least one individual driver mutation was monitored with very high sensitivity in each patient using digital droplet PCR from ctDNA. We aimed to obtain predictive markers for therapy response and survival.

\section{Materials and methods}

\section{Patients and clinical data}

We included metastasized melanoma patients of the Center for Dermatooncology of the University of Tuebingen, who started systemic treatment from January 2018 on and whose tumor tissue was available for tumor sequencing. Written consent for the participation in the study was obtained from all patients and informed consent was also given according to the Gene Diagnostic Law in Germany. Response was calculated as percentage of responses among all patients and was assessed by comparison of patients' CTs before initiation of combined immunotherapy and first staging thereafter. The baseline tumor load and response to therapy was assessed by oncologic experienced radiologists according to RECIST 1.1. [24]. To obtain a score for tumor load, the five largest lesions in each CT were measured and summed to a "CT score". In one patient with stable disease in the sum at first staging, the second staging three months later was also considered, resulting in progressive disease (PD). Two patients who had no follow-up imaging due to rapid clinical progression as assessed by the physician were classified as having progressive disease. Two patients died due to other reasons than progressive disease, one suffered myocardial infarction, the other one had pre-existing cardiac disease and died of decompensated heart failure. Both patients had exhibited an excellent response to treatment. They were considered as censored cases for the melanoma specific survival analyses.

The ethics committee of the Ärztekammer BadenWürttemberg and the local ethics committee of the Eberhard Karls University approved this study (approval numbers F-2016-010 and 827/2018BO2).

The formalin-fixed paraffin-embedded tissue that had been used for sequencing was the latest available tissue, usually metastases that had been removed recently. In 21 patients, PD-L1 status had been determined as part of the clinical routine. All samples were stained with an antibody against PD-L1 (28-8, 1100, Abcam, Cambridge, UK). Primary antibody detection was performed using the OptiView DAB IHC detection kit (Ventana). Blood samples for ctDNA were taken at the same time as the laboratory controls, which were indicated in context of the immunotherapy.

In this evaluation, we included 35 patients with combined ipilimumab and nivolumab treatment and assessment of treatment response until August 17 th 2018.

\section{Cell-free DNA and tumor sequencing}

In all patients, a tumor panel of 710 tumor-associated genes was analyzed (tumor vs. reference tissue 
comparison), followed by repetitive liquid biopsies every 3-4 weeks.

\section{Tumor panel analysis}

From EDTA blood and tumor samples (primary tumor, metastasis), genomic DNA was isolated according to the manufacturers' instructions using QIAamp DNA Blood Maxi Kit on a QiaSymphony instrument (Qiagen, Hilden, Germany) or blackPREP FFPE DNA Kit (Analytik Jena, Jena, Germany), respectively. DNA isolation of tumor DNA was performed after macro dissection by pathologist or neuropathologist. DNA quantity and quality were determined using Qubit ${ }^{\circ}$ Fluorometer (Thermo Fisher Scientific, Dreieich, Germany) and Fragment Analyzer (AATI, Heidelberg, Germany), respectively. All coding regions and flanking intronic regions of 710 genes were enriched using Agilent in-solution baithybridization technology. For sequencing we used either Illumina HiSeq2500, HiSeq4000, or NovaSeq6000 systems (Illumina, San Diego, USA).

\section{Isolation of plasma and cell-free DNA and ddPCR analysis}

Whole blood was collected in either EDTA tubes or in cell-free BCT tubes (Streck, cat. no. 218992). From these, plasma was isolated by a double centrifugation protocol $\left(1900 \mathrm{~g}, 10 \mathrm{~min}, 4^{\circ} \mathrm{C}\right.$ and $16,000 \mathrm{~g}, 10 \mathrm{~min}$, $\left.4{ }^{\circ} \mathrm{C}\right)$. Cell-free DNA was extracted from $4 \mathrm{ml}$ plasma using MagMAX Cell-Free DNA Isolation Kit (ThermoFisher, cat. no. A29319). Quality and quantity of cell-free DNA were analyzed using High Sensitivity NGS Fragment Analysis Kit (AATI, cat. no. DNF-474) and Qubit dsDNA HS Assay Kit (ThermoFisher, cat. no. Q32854), respectively.

For digital droplet PCR, dual-probe TaqMan assays were designed to determine the presence of somatic mutations in cell-free DNA which were known from previous tumor tissue sequencing. If possible, assays were designed for therapeutically relevant mutations identified in the autologous tumor tissue. For assay design, the target region covering 80 base pairs (bp) upstream and downstream of a variant were retrieved from University of California, Santa Cruz (UCSC) Genome Browser (human genome: GRCh 38/hg38) [25]. A search by the Basic Local Alignment Search Tool (BLAST) was conducted to identify potentially present pseudogenes or other regions displaying strong homology to the target region [26]. Within the target region, common single nucleotide variants $(\mathrm{AF} \geq 1 \%)$, homologous regions as well any patient specific germline and somatic variants were masked and the variant position marked. The marked target sequence was pasted into the online design tools of Thermo Scientific or BioRad for automated assay design. In some cases, commercially available predesigned assays were ordered from Thermo Scientific or
BioRad. A list of all assays used can be found in Additional file 1: Table S1.

All ddPCR-based cell-free DNA analyses were performed (BioRad QX200 Droplet Generator and Reader, BioRad, Munich, Germany) and reported according to the digital MIQE guidelines [27] [28]. Numbers of mutant and wild-type DNA copies were calculated, and mutant allele frequencies were calculated by dividing the number of mutant DNA copies by the total number of DNA copies in the plasma sample. DNA from patients' tumor tissue and reference DNA (obtained from Coriell Institute) were used positive and negative controls, respectively.

\section{Bioinformatics}

For NGS analysis, sequencing reads were demultiplexed using Illumina bcl2fastq (1.8.2). Adapter sequences were removed with Skewer 0.1.116 and the trimmed reads mapped to the human reference genome (hg19) using the Burrows Wheeler Aligner (BWA-mem 0.7.2). Reads mapping to more than one location with identical mapping scores were discarded. Duplicates resulting from PCR amplification and nonuniquely mapping reads were removed (CeGaT proprietary software). Variants were called and technical artefacts removed (CeGaT proprietary software). The resulting variants were annotated based on several internal and external databases.

For each patient, both, tumor tissue as well as reference tissue were analyzed and the data compared to reliably distinguish somatic mutations from germline variants.

TMB was defined as the number of somatic single nucleotide variants, InDel-, and essential splicing changes in the complete coding region (exome) and reported as mutations (Mut) per one million coding bases (Mb). To compute tumor mutation burden, first the somatic variants affecting the protein-coding regions of all sequenced genes (both synonymous as well as nonsynonymous) with a minimum variant frequency of $10 \%$ were counted. Variants identified by 710 gene panel sequencing were split into driver and passenger mutations and the resulting two counts used to estimate the number of somatic variants in the whole exome. For this estimation, passenger mutations were assumed to occur with equal density in all known genes, i.e., their number was scaled up relative to the difference between gene panel size and whole exome size. Driver mutations were assumed to be limited to tumor-associated genes, and their number was not scaled up. The estimated total count of both passenger and driver mutations was normalized to the size of the complete coding exome. The classification of the determined mutation load per encoding Megabase DNA was carried out in the categories 
"low" (< 3.3 Mut/Mb) "intermediate" (3.3-23.1 Mut/Mb) and "high" (> 23.1 Mut/Mb) [29] [14].

\section{Statistical analysis}

Statistical analysis was performed using the statistical program for social sciences SPSS Version 25 (IBM, New York, United States) and R (Version 3.4.4, R Core Team, 2018). Descriptive statistics were used to describe the study collective. The distribution of TMB in responders and non-responders was compared using the nonparametric Wilcoxon Rank-Sum test as implemented in R. Differences between groups were tested using the Exact Fisher test and the Exact Version of the Chi-Square trend test for categorical data (response and comparisons between potential predictors) and the Log rank test (melanoma specific survival). Survival curves were generated according to the Kaplan-Meier method: Survival time was defined as the time between first cycle of ipilimumab+nivolumab and melanoma specific death, or censored at the last date of patient contact. It was not possible to perform multivariate (logistic or Cox) regression analysis, probably due to the relatively small number of cases. None of the models with two predictors converged using the iterative algorithm of SPSS for maximum likelihood estimation. Thus, for the relevant pairs of predictors (TMB in combination with detection of ctDNA, increase of ctDNA or cell-free DNA at first follow-up, liver metastasis, or sex), we built combined variables with three to six categories each. Then we performed the Exact Version of the Chi-Square trend test for categorical data and Kaplan Meier analysis with Log rank test for these combined variables. The level of significance was 0.05 (two-sided) in all analyses. Adjustment for multiple testing was not performed.

\section{Results}

\section{Patient cohort}

We prospectively included advanced melanoma patients that started a new systemic treatment from January 2018 on and whose tumor tissue was available for tumor sequencing. In this evaluation, we only included 35 patients that started treatment with ipilimumab and nivolumab in the time from January 8th to May 24th 2018. The following melanoma subtypes were involved: $20(57 \%)$ cutaneous, 6 (17\%) occult, 4 (11\%) uveal, 3 (9\%) acral and $2(6 \%)$ mucosal melanomas. About half of the patients were female $(46 \%)$ and the largest part of the patients $(63 \%)$ started ipilimumab and nivolumab as their first line systemic treatment. 10 patients (29\%) had been treated with targeted therapy before and 3 (9\%) with PD-1 antibodies. $89 \%$ of the tissues sequenced were therapy naive, $43 \%$ issued from lymph node metastases, $51 \%$ from other than lymph node metastases and in 6\% the primary melanoma was used for sequencing as no metastasis was accessible. Median time until the first staging was 69 days (IQR 49-80), median follow-up since start of combined immunotherapy was 213 days (IQR 175-272).

PD-L1 status was not determined in this prospective study, but in the routine of clinical care it was assessed in $21 / 35$ patients $(60 \%)$. PD-L1 $<1 \%$ was found in 11 patients (31\%), PD-L1 $\geq 1 \%$ in 10 patients (29\%). In 14 patients $(40 \%)$ there was no determination of PD-L1 expression.

17 patients $(49 \%)$ completed 4 cycles of combined immunotherapy, 8 (23\%) received 3 cycles, 7 (20\%) 2 cycles and 3 patients only received one cycle. One of these three patients had rapid progression and died. Another suffered severe myocarditis and diabetes mellitus and therefore continued nivolumab alone. A third patient refused further treatment.

Baseline lactate dehydrogenase (LDH) was elevated in $40 \%$ of the patients and about one third of the patients had liver or brain metastases respectively. $63 \%$ of the patients suffered adverse events (AE) of CTCAE grade 3 or 4. Median time until onset of these AE was 42 days (IQR 21-61) (Table 1). Among all non-responders, 12 suffered adverse events grade 3 or 4 .

\section{Cell-free DNA and tumor sequencing}

Results of tumor sequencing were obtained for all 35 patients. Due to qualitative deficiencies, no TMB could be determined in 5 samples: in two samples the material did not yield a sequencing library of sufficient complexity resulting in very low coverage. One sample was contaminated. In two samples the tumor content was too low.

Median tumor mutation burden was 4.7 Mut/Mb (IQR 2-17). Categorized in 3 TMB groups as published before $[14,29]$, there were 11 (37\%) classified low $(<3.3$ Mut/Mb), 13 (43\%) intermediate (3.3-23.1 Mut/Mb) and $6(20 \%)$ high (> 23.1 Mut/Mb).

Cell-free DNA was collected at baseline for $34 \mathrm{pa}-$ tients. At time point 2, ddPCR could be obtained from 32 patients, at time point 3 from 28 patients, and at time point 4 from 25 patients. Median time between baseline and first follow-up cell-free DNA samples was 23 days (IQR 21-29). Somatic mutations in the following genes were analyzed in the patients' plasma: $B R A F, C D K 4$, GNAQ, JAK2, KRAS, MAP2K1, NF1, NRAS, STAT1 (mutations indicated in Additional file 1: Table S1).

Published cutoffs for high TMB are supported by our data We sought to determine whether our cohort supports previously published thresholds stratifying patients into TMB-high and not-high groups. A recently published study including 321 melanoma patients suggested a threshold of $30.7 \mathrm{Mut} / \mathrm{Mb}$ using the MSK-Impact panel 
Table 1 Clinical characteristics of the cohort

\begin{tabular}{|c|c|c|c|}
\hline Patients` characteristics $(n=35)$ & median & IQR & range \\
\hline Age at first diagnosis of melanoma (years) & 55 & $47-70$ & $\begin{array}{l}17- \\
79\end{array}$ \\
\hline $\begin{array}{l}\text { Time between primary diagnosis and first distant } \\
\text { metastasis (months) }\end{array}$ & 17 & $5-43$ & $\begin{array}{l}0- \\
241\end{array}$ \\
\hline $\begin{array}{l}\text { Time between start of combined immunotherapy and } \\
\text { first staging (days) }\end{array}$ & 69 & $49-80$ & $\begin{array}{l}12- \\
108\end{array}$ \\
\hline \multirow[t]{2}{*}{$\begin{array}{l}\text { Time between start of combined immunotherapy and } \\
\text { onset of severe adverse events (days) }\end{array}$} & 42 & $21-61$ & $\begin{array}{l}11- \\
126\end{array}$ \\
\hline & & $\begin{array}{l}\text { no. } \\
\text { patients }\end{array}$ & $\%$ \\
\hline \multicolumn{4}{|l|}{ Sex } \\
\hline Female & & 16 & 46 \\
\hline Male & & 19 & 54 \\
\hline \multicolumn{4}{|l|}{ Melanoma type } \\
\hline Cutaneous & & 20 & 57 \\
\hline Occult & & 6 & 17 \\
\hline Uveal & & 4 & 11 \\
\hline Acral & & 3 & 9 \\
\hline Mucosal & & 2 & 6 \\
\hline \multicolumn{4}{|l|}{ BRAF mutation } \\
\hline BRAF v600 positive & & 16 & 46 \\
\hline BRAF v600 negative & & 19 & 54 \\
\hline \multicolumn{4}{|l|}{ Systemic treatment before combined immunotherapy } \\
\hline None - combined immunotherapy as first line & & 22 & 63 \\
\hline Targeted therapy & & 10 & 29 \\
\hline PD1 antibody & & 3 & 9 \\
\hline \multicolumn{4}{|l|}{ LDH at start of combined immunotherapy } \\
\hline LDH elevated & & 14 & 40 \\
\hline LDH normal & & 21 & 60 \\
\hline \multicolumn{4}{|l|}{ Metastasis at start of combined immunotherapy } \\
\hline Presence of lung metastases & & 19 & 54 \\
\hline Presence of brain metastases & & 12 & 34 \\
\hline Presence of liver metastases & & 10 & 29 \\
\hline \multicolumn{4}{|l|}{ AJCC (2017) stage } \\
\hline $\mathrm{M} 1 \mathrm{a} / \mathrm{M} 1 \mathrm{~b}$ & & 11 & 31 \\
\hline M1c & & 12 & 34 \\
\hline M1d & & 12 & 34 \\
\hline \multicolumn{4}{|l|}{ Cycles of combined immunotherapy } \\
\hline 1 cycle & & 3 & 9 \\
\hline 2 cycles & & 7 & 20 \\
\hline 3 cycles & & 8 & 23 \\
\hline 4 cycles & & 17 & 49 \\
\hline \multicolumn{4}{|l|}{ Response to combined immunotherapy } \\
\hline Response & & 15 & 43 \\
\hline -- complete response & & 4 & 11 \\
\hline Progressive disease & & 20 & 57 \\
\hline Adverse events CTCAE 3-4 & & 22 & 63 \\
\hline
\end{tabular}

Table 1 Clinical characteristics of the cohort (Continued)

\begin{tabular}{lll}
\hline Patients' characteristics $(n=35)$ & no. patients & $\%$ \\
\hline Origin of tissue sequenced & 15 & 43 \\
Lymph node metastasis & 18 & 51 \\
Other metastasis & 2 & 6 \\
Primary melanoma & & \\
Status of tissue sequenced & 31 & 89 \\
Tissue therapy naïve & 4 & 11 \\
Tissue pretreated &
\end{tabular}

[19]. While an earlier publication set the threshold independent of the cancer type at 23.1 Mut/Mb using the FoundationOne panel [14], based on several hundred samples, of which 121 melanoma samples.

In our cohort, the mean TMB was 43.2 (median 23.1) for responders and 4.81 (median 3.4) for non-responders, respectively. The highest TMB of a non-responder was 17.3. As a result, all thresholds between 18 and 31 Mut/ $\mathrm{Mb}$ provided equally significant stratification (data not shown). Samstein and colleagues set their threshold of 30.7 to classify $20 \%$ of cases as "TMB-high" [19]. Using this threshold in our cohort, 6/30 (20\%) of patients are classified as "high". Our cohort thus supports both published thresholds, although TMB was determined using different methods. However, it should be noted that larger cohorts allow a more accurate threshold determination.

\section{TMB, cell-free DNA and ctDNA are associated with response}

Comparing median TMB of responders and nonresponders revealed a significant difference. Median TMB was significantly higher in patients with response to immunotherapy (Fig. 1a). When complete responders were evaluated separately, an even higher TMB value in this subgroup became evident (Fig. 1b). Response to immunotherapy also correlated significantly to $\mathrm{TMB}$, classified in the three categories: TMB high ( $>23.1 \mathrm{Mut} / \mathrm{Mb})$, intermediate (3.3-23.1 Mut/Mb) and low <3.3 Mut/Mb) [14, 29]. In addition, there was a significant difference in response, when classifying TMB into 2 classes (high versus intermediate+low) (Table 2). There was a significant sex difference between the groups $\mathrm{TMB}>23.1 \mathrm{Mut} / \mathrm{Mb}$ and $\mathrm{TMB} \leq 23.1$ Mut/Mb (Additional file 2: Table S2a): all patients with $\mathrm{TMB}>23.1 \mathrm{Mut} / \mathrm{Mb}$ were male.

While cell-free DNA can be found in blood plasma at baseline concentrations in healthy individuals and fluctuates with such factors as, e.g., physical exercise, concentrations have been reported to be elevated in patients with progressive disease as well as during the initial stages of a successful tumor therapy, when a large number of tumor cells perish [30]. We measured cell-free DNA concentrations (i.e., the concentration of cell-free DNA regardless of whether such DNA was tumor- 


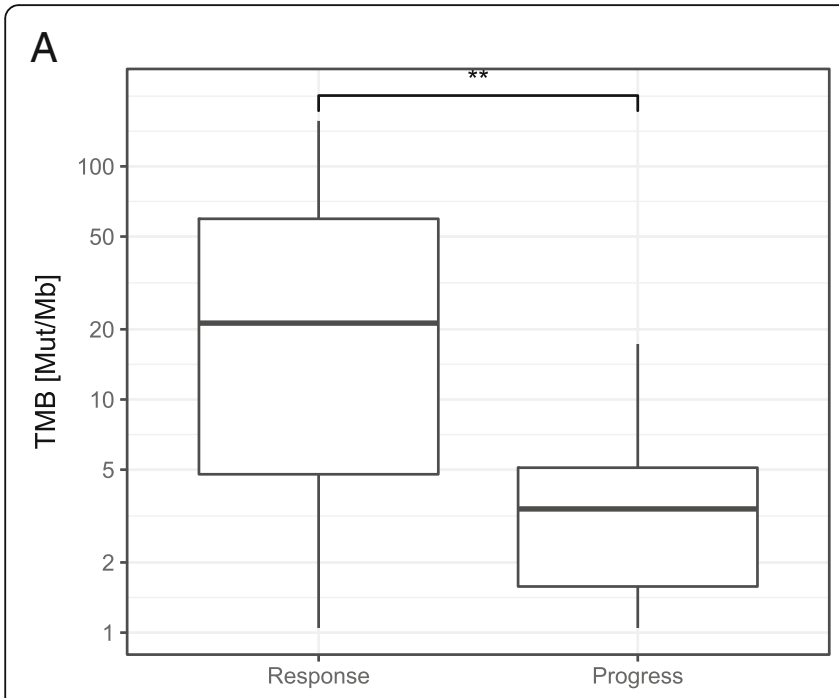

Significance (Wilcoxon Rank-Sum test) is 0.0062
B

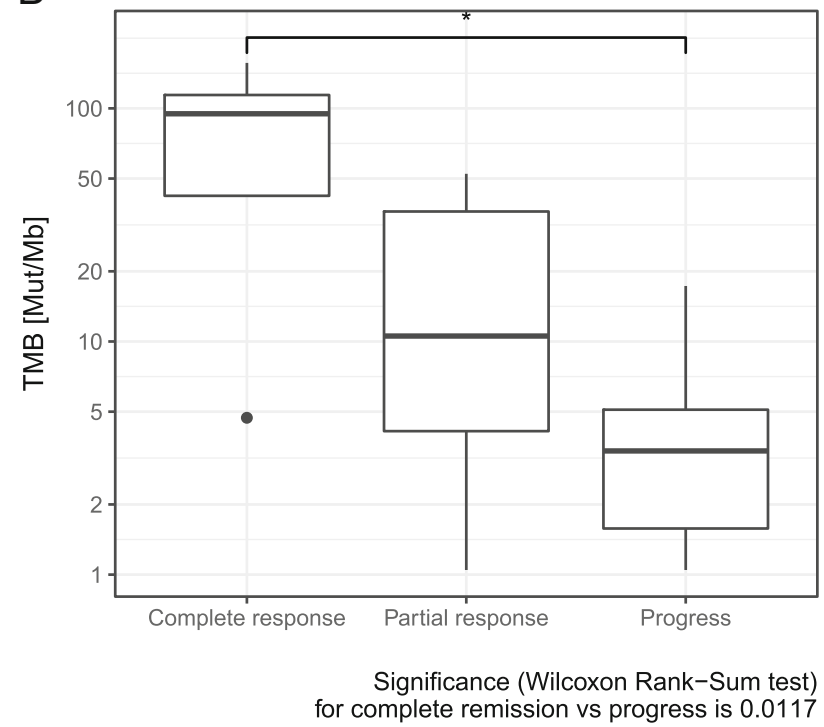

Fig. 1 a Comparison of tumor mutation burden (TMB) in responders and non-responders to combined immunotherapy. $\mathbf{b}$ Comparison of tumor mutation burden (TMB) in complete responders, partial responders, and non-responders to combined immunotherapy

derived or not) as well as tumor-specific variant copies/ $\mathrm{ml}$ of plasma for each patient quantified by digital droplet PCR (ddPCR). The tumor-derived cell-free DNA, i.e. circulating tumor DNA (ctDNA) is measured as tumor specific variant copies/ml of plasma. ddPCR is a very sensitive method and allows to detect ctDNA at allele frequencies of $>0.2 \%$ from $5 \mathrm{ng}$ of DNA if three independent observations (droplets) are set as threshold of detection.

Increasing cell-free DNA concentration was observed more often in progressive patients (Fig. 2a, Table 2). Accordingly, a decrease $>50 \%$ of cell-free DNA concentration at first follow-up, 3 weeks after treatment initiation, was significantly associated with response to combined immunotherapy (Table 2).

Increase in ctDNA copies at first follow-up occurred almost exclusively in progressive patients. In all but one therapy responders (with TMB high), ctDNA decreased or remained stable already during the first follow-up control (Fig. 2b, Table 2). Likewise, ctDNA remaining or becoming undetectable at first follow-up was significantly more common in responders. Only four of 18 patients with detectable ctDNA at first follow-up responded to combined immunotherapy (Table 2). In 8 of the 12 progressive patients suffering adverse events grade 3 or 4, ctDNA was detectable at first follow-up.

It is remarkable that ctDNA was detectable even with very low tumor load in baseline or follow-up CT. Also, a number of patients with low initial CT scores but progress at first follow-up already showed high ctDNA counts at the start of therapy (Additional file 3: Figure S3).
Regarding the combined variables (Table 3), no patient with $\mathrm{TMB} \leq 23.1 \mathrm{Mut} / \mathrm{Mb}$ and either ctDNA increase or ctDNA detectable or cell-free DNA increase of $>50 \%$ at first follow-up responded to immunotherapy. If patients with $\mathrm{TMB} \leq 23.1 \mathrm{Mut} / \mathrm{Mb}$ were responders, they had neither ctDNA increase nor ctDNA detectable at first follow-up.

\section{TMB, cell-free DNA and ctDNA are associated with overall survival}

In the mono-variate overall survival analysis according to Kaplan-Meier, > 50\% increasing cell-free DNA, detectable or increasing ctDNA at first follow-up were significant negative influence factors on overall survival. Furthermore, patients with high TMB showed a trend towards prolonged survival (Fig. 3a-d) (Table 2).

Regarding the combined variables (Table 3 ), overall survival was worse in patients with $\mathrm{TMB} \leq 23.1 \mathrm{Mut} / \mathrm{Mb}$ and either ctDNA increase or ctDNA detectable or cellfree DNA increase of $>50 \%$ at first follow-up. If $\mathrm{TMB}$ was low, survival was improved if there was no increase or detection of ctDNA at first follow-up (Fig. 4a-c).

\section{Other prognostic factors}

The presence of liver metastases also had a significant negative impact on response (Table 2). Furthermore, there was a trend towards lower response rate for patients with elevated $\mathrm{LDH}$ at the beginning of combined immunotherapy, for women, for patients that had been under treatment with targeted therapy before starting ipilimumab and nivolumab, and for patients with PD-L1 expression $<1 \%$ (Table 2). Only $2 / 11$ (18\%) patients with 
Table 2 Impact of patients' and disease characteristics on treatment response and overall survival since the beginning of combined immunotherapy

\begin{tabular}{|c|c|c|c|c|c|}
\hline & Total $n=35$ & Responder $n=15$ & Non-Responder $n=20$ & Response $P$ value & Overall survival $P$ value \\
\hline \multicolumn{6}{|l|}{ TMB [Mut/Mb] } \\
\hline$>23$ & 6 & 6 & 0 & $0.002^{1^{*}}$ & $0.06^{2}$ \\
\hline$\leq 23$ & 24 & 6 & 18 & & \\
\hline \multicolumn{6}{|c|}{ ctDNA [copies/ml] detection ${ }^{5}$} \\
\hline Not detectable & 14 & 10 & 4 & $0.011^{1^{*}}$ & $0.006^{2^{*}}$ \\
\hline Detectable & 18 & 4 & 14 & & \\
\hline \multicolumn{6}{|c|}{ ctDNA [copies/ml] increase ${ }^{5}$} \\
\hline Not increasing & 20 & 12 & 8 & $0.008^{1^{*}}$ & $0.03^{2^{*}}$ \\
\hline Increasing & 11 & 1 & 10 & & \\
\hline \multicolumn{6}{|c|}{ Cell-free DNA [ng/ml] ${ }^{6}$} \\
\hline Decrease $>50 \%$ & 7 & 5 & 2 & $0.022^{3^{*}}$ & $0.005^{4^{*}}$ \\
\hline Stable & 15 & 7 & 8 & & \\
\hline Increase > 50\% & 9 & 1 & 8 & & \\
\hline \multicolumn{6}{|c|}{ LDH baseline elevated } \\
\hline No & 21 & 11 & 10 & $0.296^{1}$ & $0.001^{2^{*}}$ \\
\hline Yes & 14 & 4 & 10 & & \\
\hline \multicolumn{6}{|c|}{ Targeted therapy before } \\
\hline No & 25 & 12 & 13 & $0.458^{1}$ & $0.001^{2^{*}}$ \\
\hline Yes & 10 & 3 & 7 & & \\
\hline \multicolumn{6}{|l|}{ Sex } \\
\hline Male & 19 & 11 & 8 & $0.087^{1}$ & $0.005^{2^{*}}$ \\
\hline Female & 16 & 4 & 12 & & \\
\hline \multicolumn{6}{|c|}{ Liver metastasis baseline } \\
\hline No & 25 & 14 & 11 & $0.022^{1^{*}}$ & $0.013^{2^{*}}$ \\
\hline Yes & 10 & 1 & 9 & & \\
\hline \multicolumn{6}{|l|}{ PD-L1 Expression } \\
\hline$\geq 1 \%$ & 10 & 6 & 4 & $0.080^{1}$ & $0.772^{2}$ \\
\hline$<1 \%$ & 11 & 2 & 9 & & \\
\hline
\end{tabular}

* significant (in bold).

${ }^{1}$ Exact Test of Fisher

${ }^{2}$ Log rank test

${ }^{3}$ Exact Chi-Square Test for Trend (Monte Carlo Simulation)

${ }^{4}$ Log rank test for Trend

${ }^{5} \mathrm{ctDNA}$ measured by tumor-specific variant [copies/ml plasma] at first follow-up after start of combined immunotherapy

${ }^{6}$ Cell-free DNA [ng/ml plasma] at first follow-up after start of combined immunotherapy

PD-L1 expression < $1 \%$ responded, but 6/10 (60\%) with at least $1 \%$ PD-L1 positivity. Concerning the presence of liver metastasis, LDH elevation, PD-L1 expression, and targeted therapy before combined immunotherapy, there were no significant differences between the two TMB groups (Additional file 2: Table S2a). It is noteworthy that patients with $\mathrm{TMB} \leq 23.1 \mathrm{Mut} / \mathrm{Mb}$ and liver metastases had an even worse prognosis than those without liver metastases (Fig. 4d). Elevated baseline $\mathrm{LDH}$, presence of liver metastases baseline, pretreatment with targeted therapy, and female sex were significant negative influence factors on overall survival in our cohort (Fig. 3e-h). The survival difference between men and women (Fig. 3f) cannot completely be explained by the fact that all TMB-high patients were male. Even in TMB-low patients, women had a worse prognosis (Fig. 4e).

\section{Discussion}

In our prospective biomarker study, response and OS of melanoma patients treated with combined immunotherapy could be shown to be positively associated with high $\mathrm{TMB},>50 \%$ decreasing cell-free DNA or undetectable ctDNA at first follow-up. Combination of TMB and cell- 


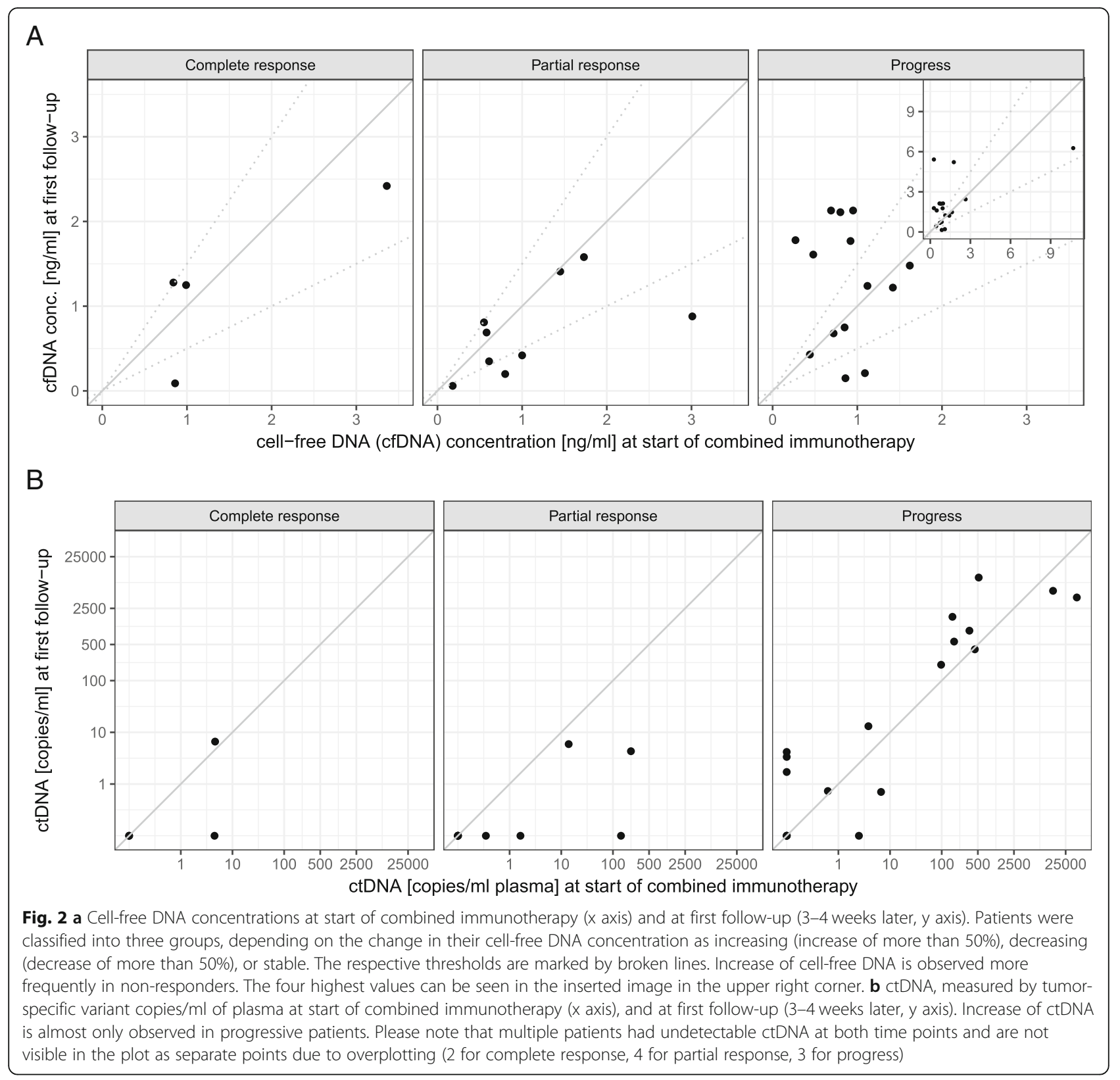

free or ctDNA were even more important. No patient with $\mathrm{TMB} \leq 23.1 \mathrm{Mut} / \mathrm{Mb}$ and either ctDNA increase or ctDNA detectable, or cell-free DNA increase of $>50 \%$ at first follow-up responded to immunotherapy. Up to now it has only been reported that higher TMB and decreasing ctDNA in melanoma patients is significantly associated with response and overall survival (OS) to checkpoint inhibitor monotherapy, but not in detail to combined immunotherapy and not the combination of TMB and ctDNA [12, 13, 15, 19, 20, 22, 31, 32].

Melanomas belong to the tumors with the highest mutation burden, most probably attributed to DNA damage by UV light [11, 29, 33]. Within all melanomas, cutaneous melanomas harbor a significantly higher mutation load than melanomas at UV-protected sites such as acral melanoma, mucosal melanoma, or uveal melanoma [29, 34-36]. A positive correlation between high mutation load of the tumor and better response to immunotherapy is not surprising: the more mutations a tumor genome contains, the higher the chance that neo-antigens are presented on its surface, which render the tumor more recognizable by $\mathrm{T}$ cells $[37,38]$. In lung cancer it has recently been shown that higher TMB correlated with better response to combined immunotherapy [39]. In melanoma such significant correlation has not been shown yet.

Kaplan-Meier curves display a trend for better survival for $\mathrm{TMB}>23.1 \mathrm{Mut} / \mathrm{Mb}$ compared to $\mathrm{TMB} \leq 23.1 \mathrm{Mut} /$ 
Table 3 Impact of patients' and disease characteristics (combined variables) on treatment response and overall survival since the beginning of combined immunotherapy

\begin{tabular}{|c|c|c|c|c|c|}
\hline & Total $n=35$ & Responder $n=15$ & Non-Responder $n=20$ & Response $P$ value & Overall survival $P$ value \\
\hline \multicolumn{6}{|c|}{ Combination of TMB [Mut/Mb] and ctDNA [copies/ml] detection ${ }^{3}$} \\
\hline $\begin{array}{l}\text { TMB }>23 \text { Mut/Mb } \\
+ \text { ctDNA not detectable }\end{array}$ & 3 & 3 & 0 & $<0.0001^{1^{*}}$ & $0.005^{2^{*}}$ \\
\hline $\begin{array}{l}\text { TMB }>23 \text { Mut/Mb } \\
+ \text { ctDNA detectable }\end{array}$ & 3 & 3 & 0 & & \\
\hline $\begin{array}{l}\text { TMB } \leq 23 \text { Mut/Mb } \\
+ \text { ctDNA not detectable }\end{array}$ & 8 & 5 & 3 & & \\
\hline $\begin{array}{l}\mathrm{TMB} \leq 23 \mathrm{Mut} / \mathrm{Mb} \\
+\mathrm{ctDNA} \text { detectable }\end{array}$ & 13 & 0 & 13 & & \\
\hline \multicolumn{6}{|c|}{ Combination of TMB [Mut/Mb] and ctDNA [copies/ml] increase ${ }^{3}$} \\
\hline $\begin{array}{l}\text { TMB }>23 \text { Mut/Mb } \\
+ \text { ctDNA not increasing }\end{array}$ & 4 & 4 & 0 & $<0.0001^{1^{*}}$ & $0.032^{2^{*}}$ \\
\hline $\begin{array}{l}\text { TMB }>23 \text { Mut/Mb } \\
+ \text { ctDNA increasing }\end{array}$ & 1 & 1 & 0 & & \\
\hline $\begin{array}{l}\mathrm{TMB} \leq 23 \text { Mut/Mb } \\
+\mathrm{ctDNA} \text { not increasing }\end{array}$ & 12 & 5 & 7 & & \\
\hline $\begin{array}{l}\text { TMB } \leq 23 \text { Mut/Mb } \\
+ \text { ctDNA increasing }\end{array}$ & 9 & 0 & 9 & & \\
\hline \multicolumn{6}{|c|}{ Combination of TMB [Mut/Mb] and cell-free DNA $[\mathrm{ng} / \mathrm{ml}]^{4}$} \\
\hline $\begin{array}{l}\text { TMB }>23 \text { Mut/Mb } \\
+ \text { cfDNA decrease }>50 \%\end{array}$ & 3 & 3 & 0 & $0.001^{1^{*}}$ & $0.016^{2^{*}}$ \\
\hline $\begin{array}{l}\text { TMB }>23 \text { Mut/Mb } \\
+ \text { cfDNA stable }\end{array}$ & 1 & 1 & 0 & & \\
\hline $\begin{array}{l}\text { TMB }>23 \text { Mut/Mb } \\
+ \text { cfDNA increase }>50 \%\end{array}$ & 1 & 1 & 0 & & \\
\hline $\begin{array}{l}\mathrm{TMB} \leq 23 \mathrm{Mut} / \mathrm{Mb} \\
+\mathrm{cfDNA} \text { decrease }>50 \%\end{array}$ & 3 & 1 & 2 & & \\
\hline $\begin{array}{l}\text { TMB } \leq 23 \text { Mut/Mb } \\
+ \text { cfDNA stable }\end{array}$ & 11 & 4 & 7 & & \\
\hline $\begin{array}{l}\mathrm{TMB} \leq 23 \mathrm{Mut} / \mathrm{Mb} \\
+\mathrm{cfDNA} \text { increase }>50 \%\end{array}$ & 7 & 0 & 7 & & \\
\hline \multicolumn{6}{|c|}{ Combination of TMB [Mut/Mb] and liver metastases } \\
\hline $\begin{array}{l}\text { TMB }>23 \text { Mut/Mb } \\
+ \text { no liver metastases }\end{array}$ & 6 & 6 & 0 & $<0.0001^{1^{*}}$ & $0.018^{2^{*}}$ \\
\hline $\begin{array}{l}\mathrm{TMB} \leq 23 \mathrm{Mut} / \mathrm{Mb} \\
+ \text { no liver metastases }\end{array}$ & 14 & 5 & 9 & & \\
\hline $\begin{array}{l}\mathrm{TMB} \leq 23 \mathrm{Mut} / \mathrm{Mb} \\
+ \text { liver metastases }\end{array}$ & 10 & 1 & 9 & & \\
\hline \multicolumn{6}{|c|}{ Combination of TMB [Mut/Mb] and sex } \\
\hline $\begin{array}{l}\text { TMB }>23 \mathrm{Mut} / \mathrm{Mb} \\
+ \text { male }\end{array}$ & 6 & 6 & 0 & $0.002^{1^{*}}$ & $0.010^{2^{*}}$ \\
\hline $\begin{array}{l}\mathrm{TMB} \leq 23 \mathrm{Mut} / \mathrm{Mb} \\
+ \text { female }\end{array}$ & 9 & 2 & 7 & & \\
\hline $\begin{array}{l}\mathrm{TMB} \leq 23 \mathrm{Mut} / \mathrm{Mb} \\
+ \text { female }\end{array}$ & 15 & 4 & 11 & & \\
\hline
\end{tabular}

* significant (in bold).

${ }^{1}$ Exact Chi-Square Test for Trend (Monte Carlo Simulation)

${ }^{2}$ Log rank test for Trend

${ }^{3} \mathrm{ctDNA}$ measured by tumor-specific variant [copies/ml plasma] at first follow-up after start of combined immunotherapy

${ }^{4}$ Cell-free DNA [ng/ml plasma] at first follow-up after start of combined immunotherapy 
A

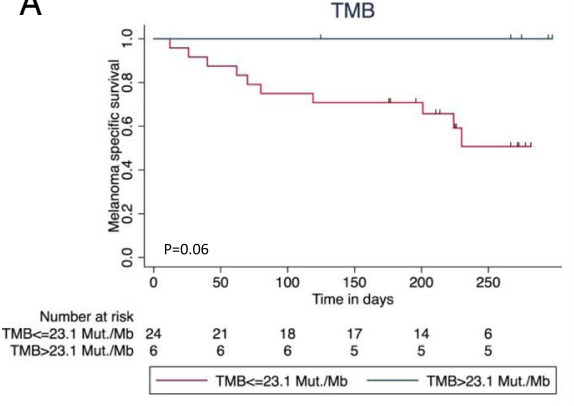

C

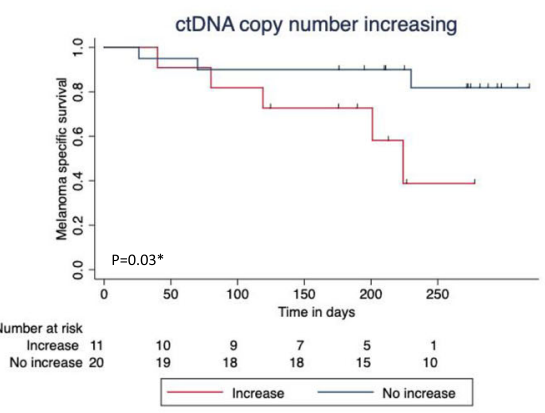

E

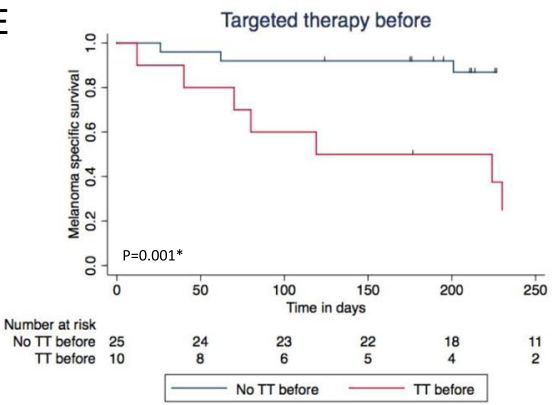

G

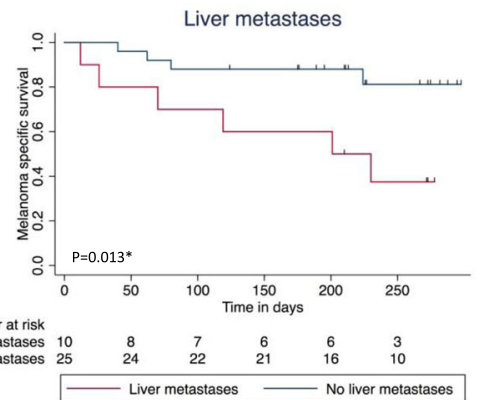

B

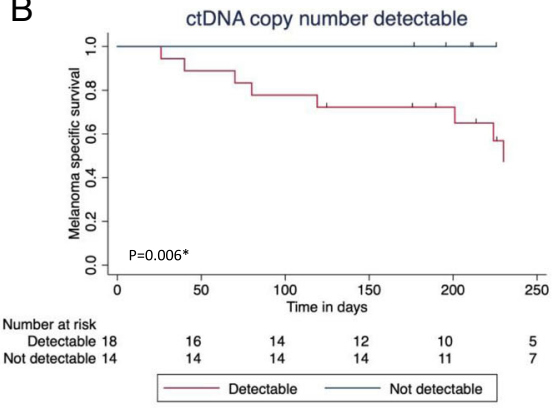

D

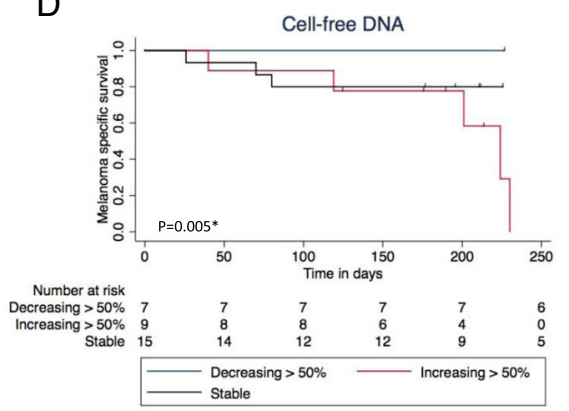

F

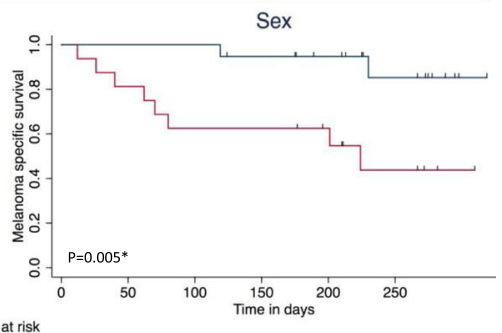

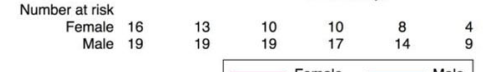

$\mathrm{H}$

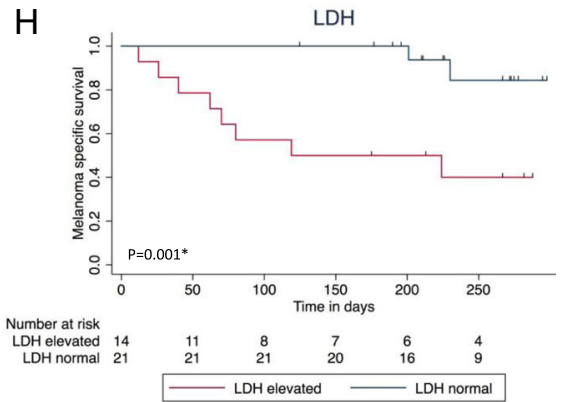

Fig. 3 Impact of baseline patients' and disease characteristics on overall survival since the beginning of combined immunotherapy. 'Log rank test $/{ }^{2}$ Log rank test for Trend. ${ }^{*}$ significant. a Tumor mutation burden (TMB) $>23.1$ Mut/Mb vs. TMB $\leq 23.1$ Mut/Mb, $p=0.06{ }^{1}$. b ctDNA measured by tumor-specific variant copies/ml of plasma detectable vs. undetectable at first follow-up, $p=0.006^{* 1}$. c ctDNA measured by tumor-specific variant copies $/ \mathrm{ml}$ of plasma increasing vs. not increasing at first follow-up, $p=0.03^{* 1}$. $\mathbf{d}$ Cell-free DNA decrease $>50 \%$ vs. stable vs. increase $>50 \%, p=$ $0.005^{* 2}$. e Targeted treatment (TT) before start of combined immunotherapy vs. no TT before, $p=0.001^{* 1}$. f Men vs. women, $p=0.005^{* 1}$. $\mathbf{g}$ Liver metastasis baseline vs. no liver metastasis baseline, $p=0.013^{* 1}$. $\mathbf{h}$ LDH baseline normal vs. elevated, $p=0.001^{* 1}$

Mb. When dealing with TMB, it has to be mentioned that remarkably rather different thresholds have been chosen. Snyder and colleagues found significant improved OS in ipilimumab-treated melanoma patients with $\mathrm{TMB}>100$, determined by whole exome sequencing [13]. In contrast, Morrison and colleagues failed to reveal significant differences in OS of melanoma patients with immunotherapy by applying a threshold which was 

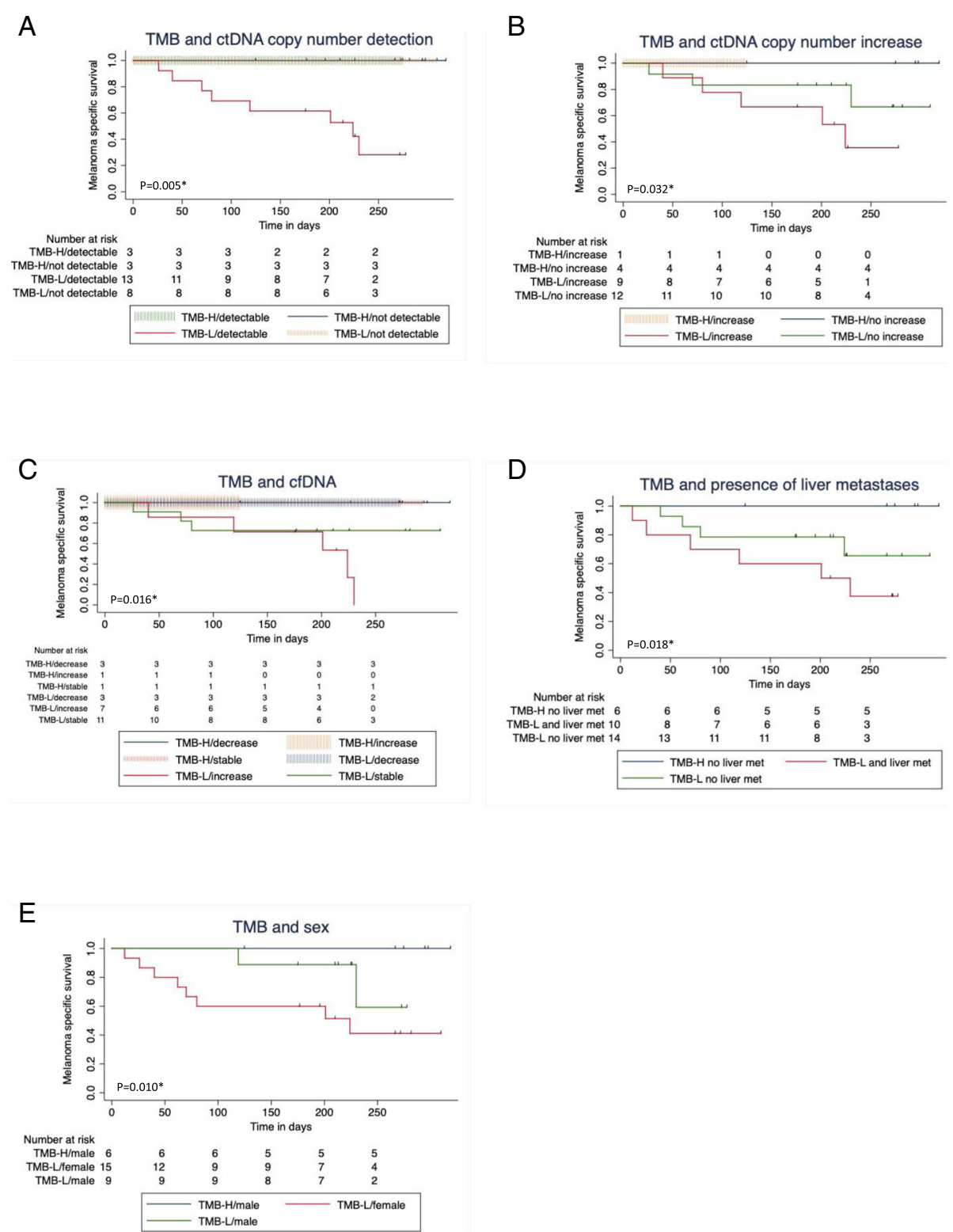

Fig. 4 Impact of combined variables of TMB on overall survival since the beginning of combined immunotherapy. TMB $>23.1 \mathrm{Mut} / \mathrm{Mb}$ (TMB-H) TMB $\leq 23.1 \mathrm{Mut} / \mathrm{Mb}(\mathrm{TMB}-\mathrm{L})$. Log rank test for Trend. ${ }^{*}$ significant. a Tumor mutation burden (TMB) and ctDNA measured by tumor-specific variant copies $/ \mathrm{ml}$ of plasma detectable vs. undetectable at first follow-up $\mathrm{p}=0.005^{*}$. b Tumor mutation burden (TMB) and ctDNA measured by tumorspecific variant copies $/ \mathrm{ml}$ of plasma increasing vs. not increasing, $p=0.032^{*}$. c Tumor mutation burden (TMB) and cell-free DNA decrease $>50 \%$ vs. stable vs. increase $>50 \%$ at first follow-up, $p=0.016^{*}$. $\mathbf{d}$ Tumor mutation burden (TMB) and presence of liver metastases, $p=0.018^{*}$. e Tumor mutation burden (TMB) and sex, $p=0.010^{*}$

determined by doubling the median and amounted to 7.1 Mut/Mb [40]. For completeness it should be mentioned that we have also made the evaluation with a TMB cut-off of 2 times the median (9.4) for comparison purposes. There was also a significant association with the response rate, but no association with OS. Recently it has been reported that among cancer patients with immunotherapy, those with higher TMB (the highest $20 \%$ of each cancer type) had a better survival.
Regarding melanoma patients, the cut-off was 30.7 Mut/ $\mathrm{Mb}$ [19]. Interestingly, all of our patients in the group > 23.1 Mut/Mb were also above $30.7 \mathrm{Mut} / \mathrm{Mb}$. It is also noteworthy that this group of patients with $\mathrm{TMB}>23.1$ accounts for the $20 \%$ highest TMB values in our cohort. Therefore our results fit very well with those of Samstein et al. [19].

Rowe and colleagues recently reported a sensitivity and specificity of ctDNA in the detection of melanoma 
metastases of 87 and 100\%. A higher tumor load was positively associated with the detection of ctDNA [21, 41]. The presence of visceral metastases such as liver metastases had been shown to increase the detectability of ctDNA in the plasma, in contrast to metastases exclusively confined to pulmonal or cerebral localization [21].

In our cohort, there was no significant difference in the Exact Test of Fisher between the presence of liver metastases and neither baseline ctDNA (data not shown), nor detectable ctDNA or increasing ctDNA at first follow-up (Additional file 2: Table S2b-c). However, the number of patients with liver metastases in our cohort was low and a strong tendency towards correlation cannot be dismissed. We were able to collect early follow-up cell-free DNA and ctDNA approximately every three weeks and the comparison of the follow-up values to baseline allowed us to assess a tendency for response.

It is remarkable that no patient with $\mathrm{TMB} \leq 23.1 \mathrm{Mut} /$ $\mathrm{Mb}$ and either ctDNA increase or ctDNA detectable or cell-free DNA increase of $>50 \%$ at first follow-up responded to immunotherapy. These results offer the possibility of estimating a therapy response at a very early time point, already at first follow-up. In case of severe adverse events early after treatment initiation, this could be helpful in the decision whether to continue immunotherapy or not. In our cohort, $67 \%$ of the progressive patients suffering at least grade 3 adverse events had detectable ctDNA at the first follow-up.

In other studies, the predictive value of response in the first staging was significant for melanoma patients with either no detection of ctDNA baseline or with positive baseline ctDNA becoming undetectable within 12 weeks of immunotherapy. Furthermore, ctDNA was shown to be superior to other baseline parameters, such as ECOG performance status, LDH, or tumor burden [20]. However, in some of these studies liquid biopsies were obtained at different time points, or less than $50 \%$ of blood samples were available at time point 3-4 weeks after the start of therapy [20]. Ashida and colleagues reported that decreasing levels of ctDNA already three weeks after immunotherapy initiation were found in all melanoma patients responsive to pembrolizumab but not in the progressive ones [32]. These results corroborate our results, pointing out that one can already evaluate treatment response at a very early stage. In another study an early therapy response to immunotherapy by means of PETCT has been determined, changing the way of thinking that success or failure of an immunotherapy should be evaluated at the earliest 12 weeks after initiation [42]. However we and Ashida found that already the very first follow-up of cell-free DNA / ctDNA within 3-4 weeks after therapy initiation could provide information about response / non-response.
We decided to include analysis of cfDNA (i.e., total cell-free DNA, not limited to tumor-derived DNA only) in our evaluation as the amount of cfDNA per ml plasma can be determined more readily than the number of tumor-derived copies of DNA (ctDNA). This is particularly important when no patient-specific ddPCR assay is available. cfDNA levels can thus be used as an early marker and should also be considered in follow-up analyses even if ctDNA is determined by ddPCR as well. Successful therapy can suppress a tumor clone carrying the queried mutation while other clones without that mutation may thrive. In ctDNA analysis of the targeted mutation, this would result in a reduction of the observed ctDNA with simultaneously increasing concentration cfDNA. Using both markers together can thus help to increase the sensitivity of detecting progress.

We were able to offer the possibility of detecting genes other than BRAF and NRAS in the plasma. We used either commercially available or individually designed ddPCR assays to detect individual somatic variants identified in previous tumor tissue sequencing (Additional file 1: Table S1). This means that for almost any patient, even triple wildtype patients, an individual variant could be monitored by using liquid biopsy. In the future the sensitivity of such analysis may be increased by raising the cell-free DNA input amount per ddPCR analysis (here $5 \mathrm{ng}$ was used for most cases) and by extending this analysis to several known somatic mutations per patient with a potential huge impact in determining treatment success if this becomes available for every patient in a clinical routine.

Our observed sex-specific difference in ORR and OS of melanoma patients treated by immune checkpoint inhibitors are further strengthened by a large metaanalysis including 3632 melanoma patients. This study revealed quite obviously that male metastasized melanoma patients treated by immunotherapy had a better outcome than female melanoma patients. The pooled survival rate for men was double that for women [43]. It has to be considered that Gupta and colleagues reported a significant higher median TMB in male melanoma patients than in female ones. Of note, melanoma was the only tumor in which they found this sex difference, also in lung carcinoma there was no sex difference in TMB [44]. On the other hand, Xiao and colleagues also found higher TMB in male patients with lung adenocarcinoma [45]. Indeed, a higher TMB in male melanoma patients could provide an explanation for the different outcome between male and female melanoma patients treated by immune checkpoint inhibitors. Nevertheless, even if there was a significant sex difference in the two TMB groups of our cohort (Additional file 2: Table S2a), worse prognosis for women was still obvious when comparing only TMB low patients (Fig. 4e). Likewise, Goodman 
and colleagues found a significant sex difference in their cohort of melanoma and NSCLC patients: $76 \%$ of the patients with TMB high were male $(p=0.035)$. In multivariate analysis, TMB remained a significant influence factor on response to immunotherapy, not sex [15].

The negative impact of liver metastases on response and OS of patients with anti-PD-1 therapy has already been shown, but again not concerning combined immunotherapy [9, 46, 47]. To the best of our knowledge, this is the first study to demonstrate both, better ORR and OS in patients without liver metastases. Remarkably, ORR and $\mathrm{OS}$ of patients with $\mathrm{TMB} \leq 23.1 \mathrm{Mut} / \mathrm{Mb}$ were even worse if additional liver metastases were present (Fig. 4d).

Combined immunotherapy after progress under targeted therapy was not successful in our cohort. This emphasizes the high medical need to carefully decide about first line treatment. Nevertheless it cannot be excluded that the patients that had been treated with targeted therapy before had a higher initial tumor load at the onset of metastasis and thus a worse prognosis anyway. We are therefore eagerly awaiting current studies (NCT02631447 / NCT03235245) on the topic of the best therapy sequence.

The size of our panel (710 genes, $2.1 \mathrm{MB}$ ) allows us to make a quite precise calculation of the TMB. A recent study found that a minimum size of $1.5 \mathrm{Mb}$ is required to achieve accurate TMB values [23]. In addition, by sequencing both, tumor and normal tissue we can accurately detect somatic and germline variants. Shi et al. [48] compared tumor-only and matched-normal analysis pipelines and reported that tumor-only analysis falsely classified a significant number of germline variants $(62 \%)$ as somatic, potentially skewing TMB towards higher values.

The extent of metastasis of the patients in our cohort was the same as in other studies, with the exception of cerebral metastases, which were otherwise excluded. Like others we had about $30 \%$ of patients with baseline liver metastases [9], about $40 \%$ of the patients had elevated baseline $\mathrm{LDH}$ at the beginning of combined immunotherapy and slightly more men were included [5]. Furthermore, CT evaluation was performed in the median 69 days after treatment initiation. As radiological response is usually evident within the first 12 weeks of treatment, this period seems to be appropriate [49]. The occurrence of grade 3 or 4 toxicity was $63 \%$ in our study corresponding to that of other studies [4].

Nevertheless, our results should be validated in a larger cohort and it remains unclear whether patients with low TMB and manifest liver metastases should start with a targeted therapy in the presence of a BRAF mutation instead of combined immunotherapy. Neither multivariate analysis nor control for multiple hypothesis testing were performed, so there is a risk of false discovery in assessing many variables in a non-pre-specified manner in a small dataset.

It should also be taken into account that the follow-up time of our cohort is relatively short for reliable interpretation of survival data. Further prospective and randomized studies are indispensable.

\section{Conclusion}

Melanoma patients who are to be treated with systemic therapy should be screened and advised with regard to their individual risk factors for non-response. Presence of liver metastases and low TMB renders response to combined immunotherapy less likely. Women seem to have a disadvantage over men. Once therapy has started, $>50 \%$ increasing cell-free DNA, detectable or increasing ctDNA at first follow-up might be further indicators of non-response. The possibility of being able to detect treatment failure as early as 3 weeks after treatment initiation could become particularly important if patients suffer adverse events at an early time point of combined immunotherapy and are unsure whether to continue treatment.

Work should be done to ensure that TMB can be determined reliably and easily from a liquid biopsy, because tumor tissue is not always available and patients are not always in shape to go through surgery. Our study presents a valuable and important contribution on the way to more precision in patient selection for systemic treatment of metastasized melanoma.

\section{Additional file}

Additional file 1: Assays, either commercially available or individually designed. (DOCX $16 \mathrm{~kb})$

Additional file 2: Impact of baseline patients' and disease characteristics on tumor mutation burden, ctDNA and cfDNA. (DOCX 26 kb)

Additional file 3: Tumor load (computer tomography score), defined as the sum of diameters of the largest five metastases visible in $C T$ compared to ctDNA, measured by tumor-specific variant copies $/ \mathrm{ml}$ of plasma. Data from two assessments per patient (baseline and first followup $C T$ and corresponding ctDNA). (PDF $10 \mathrm{~kb}$ )

\section{Publisher's Note}

Springer Nature remains neutral with regard to jurisdictional claims in published maps and institutional affiliations.

\section{Acknowledgements}

We thank the whole team of the melanoma outpatient department for their care for our melanoma patients and the patients for their participation in this study.

\section{Authors' contributions}

Conception and design: AF, FB, DH, DD, SB. Development of methodology: $\mathrm{FB}, \mathrm{DH}, \mathrm{CH}, \mathrm{MF}, \mathrm{DD}, \mathrm{SB}$. Acquisition of data: AF, FB, MK, SW, DD, SB. Analysis and interpretation of data: $A F, F B, D H, M S, P M, T S, D D$. Writing, review, revision of the manuscript: $A F, F B, D H, M S, S W, B K, C G, P M, T S, D D, S B$. Approval of the submitted version: all authors. Administrative, technical, or 
material support: MK, NT, TA, TS, TE, UK, BK. Study supervision: AF, FB, DH, DD, SB. All authors read and approved the final manuscript.

\section{Funding}

The study was supported by the German Federal Ministry of Education and Research (BMBF) within the KMU-innovative initiative. AF was supported by the TÜFF Habilitation Program for Women of the Faculty of Medicine Tübingen, Germany, grant no 2521-0-0. Publication fee was supportd by Deutsche Forschungsgemeinschaft and Open Access Publishing Fund of University of Tübingen.

\section{Availability of data and materials}

The datasets used and/or analysed during the current study are available from the corresponding author on reasonable request.

\section{Ethics approval and consent to participate}

Written consent for the participation in the study was obtained from al patients and informed consent was also given according to the Gene Diagnostic Law in Germany. Ethics committee of the Ärztekammer BadenWürttemberg and local ethics committee of the Eberhard Karls University approved this study (approval numbers F-2016-010 and 827/2018BO2).

\section{Consent for publication}

Not applicable.

\section{Competing interests}

AF served as consultant to Roche, Novartis, MSD, Pierre-Fabre; received travel support from Roche, Novartis, BMS, Pierre-Fabre, received speaker fees from Cegat, Roche, Novartis, BMS, MSD. TA received travel support from Novartis. TE served as consultant to Roche, Novartis, MSD, BMS, Pierre-Fabre; received speaker fees from Roche, Novartis, BMS, MSD. CG reports grants and personal fees from Novartis, BMS, Roche, personal fees from MSD. Personal fees from Amgen, Philogen, LEO, Incyte, outside the submitted work. DD received travel support from BMS. No competing interests were declared by the other authors.

\section{Author details}

Center for Dermatooncology, Department of Dermatology, University Hospital Tuebingen, Liebermeisterstr. 25, 72076 Tuebingen, Germany. ${ }^{2}$ Center for Genomics and Transcriptomics (CeGaT) GmbH, Tuebingen, Germany. ${ }^{3}$ Practice for Human Genetics, Tuebingen, Germany. Institute for Radiology, Rems-Murr-Kliniken, Winnenden, Germany. ${ }^{5}$ Institute for Radiology, University Hospital Tuebingen, Tuebingen, Germany. ${ }^{6}$ Portuguese Air Force Health Care Direction, Lisbon, Portugal. ${ }^{7}$ Institute for Clinical Epidemiology and applied Biostatistics (IKEaB), Tuebingen, Germany.

Received: 8 February 2019 Accepted: 27 June 2019 Published online: 12 July 2019

\section{References}

1. Ribas A, Hamid O, Daud A, Hodi FS, Wolchok JD, Kefford R, et al. Association of Pembrolizumab with Tumor Response and Survival among Patients with Advanced Melanoma. Jama. 2016;315(15):1600-9.

2. Robert C, Long GV, Brady B, Dutriaux C, Maio M, Mortier L, et al. Nivolumab in previously untreated melanoma without BRAF mutation. N Engl J Med. 2015;372(4):320-30.

3. Hodi FS, Chiarion-Sileni V, Gonzalez R, Grob JJ, Rutkowski P, Cowey CL, et al. Nivolumab plus ipilimumab or nivolumab alone versus ipilimumab alone in advanced melanoma (CheckMate 067): 4-year outcomes of a multicentre, randomised, phase 3 trial. Lancet Oncol. 2018;19(11):1480-92.

4. Wolchok JD, Chiarion-Sileni V, Gonzalez R, Rutkowski P, Grob JJ, Cowey CL, et al. Overall Survival with Combined Nivolumab and Ipilimumab in Advanced Melanoma. N Engl J Med. 2017;377(14):1345-56.

5. Larkin J, Chiarion-Sileni V, Gonzalez R, Grob JJ, Cowey CL, Lao CD, et al. Combined Nivolumab and Ipilimumab or monotherapy in untreated melanoma. N Engl J Med. 2015;373(1):23-34

6. Puzanov I, Dummer R, Schachter J, Pavlick AC, Gonzalez R, Ascierto PA, et al. Efficacy based on tumor PD-L1 expression in KEYNOTE-002, a randomized comparison of pembrolizumab (pembro; MK-3475) versus chemotherapy in patients (pts) with ipilimumab-refractory (IPI-R) advanced melanoma (MEL). J Clin Oncol. 2015;33(15_suppl):3012.
7. Weber JS, D'Angelo SP, Minor D, Hodi FS, Gutzmer R, Neyns B, et al. Nivolumab versus chemotherapy in patients with advanced melanoma who progressed after anti-CTLA-4 treatment (CheckMate 037): a randomised, controlled, open-label, phase 3 trial. Lancet Oncol. 2015;16(4):375-84.

8. Madore J, Vilain RE, Menzies AM, Kakavand H, Wilmott JS, Hyman J, et al. PD-L1 expression in melanoma shows marked heterogeneity within and between patients: implications for anti-PD-1/PD-L1 clinical trials. Pigment Cell Melanoma Res. 2015;28(3):245-53.

9. Tumeh PC, Hellmann MD, Hamid O, Tsai KK, Loo KL, Gubens MA, et al. Liver metastasis and treatment outcome with anti-PD-1 monoclonal antibody in patients with melanoma and NSCLC. Cancer Immunol Res. 2017:5(5):417-24.

10. Tumeh PC, Harview CL, Yearley JH, Shintaku IP, Taylor EJ, Robert L, et al. PD1 blockade induces responses by inhibiting adaptive immune resistance. Nature. 2014;515(7528):568-71

11. Alexandrov LB, Nik-Zainal S, Wedge DC, Aparicio SA, Behjati S, Biankin AV, et al. Signatures of mutational processes in human cancer. Nature. 2013; 500(7463):415-21.

12. Van Allen EM, Miao D, Schilling B, Shukla SA, Blank C, Zimmer $L$, et al. Genomic correlates of response to CTLA-4 blockade in metastatic melanoma. Science. 2015;350(6257):207-11.

13. Snyder A, Makarov V, Merghoub T, Yuan J, Zaretsky JM, Desrichard A, et al. Genetic basis for clinical response to CTLA-4 blockade in melanoma. N Engl J Med. 2014;371(23):2189-99.

14. Johnson DB, Frampton GM, Rioth MJ, Yusko E, Xu Y, Guo X, et al. Targeted next generation sequencing identifies markers of response to PD-1 blockade. Cancer Immunol Res. 2016;4(11):959-67.

15. Goodman AM, Kato S, Bazhenova L, Patel SP, Frampton GM, Miller V, et al. Tumor mutational burden as an independent predictor of response to immunotherapy in diverse cancers. Mol Cancer Ther. 2017;16(11):2598-608.

16. Hugo W, Zaretsky JM, Sun L, Song C, Moreno BH, Hu-Lieskovan S, et al. Genomic and transcriptomic features of response to anti-PD-1 therapy in metastatic melanoma. Cell. 2016;165(1):35-44.

17. Shin DS, Zaretsky JM, Escuin-Ordinas H, Garcia-Diaz A, Hu-Lieskovan S, Kalbasi A, et al. Primary resistance to PD-1 blockade mediated by JAK1/2 mutations. Cancer Discov. 2017;7(2):188-201.

18. Roh W, Chen PL, Reuben A, Spencer CN, Prieto PA, Miller JP, et al. Integrated molecular analysis of tumor biopsies on sequential CTLA-4 and PD-1 blockade reveals markers of response and resistance. Sci Transl Med. 2017;9(379):eaah3560.

19. Samstein RM, Lee CH, Shoushtari AN, Hellmann MD, Shen R, Janjigian YY, et al. Tumor mutational load predicts survival after immunotherapy across multiple cancer types. Nat Genet. 2019;51(2):202-6.

20. Lee JH, Long GV, Boyd S, Lo S, Menzies AM, Tembe V, et al. Circulating tumour DNA predicts response to anti-PD1 antibodies in metastatic melanoma. Ann Oncol. 2017;28(5):1130-6

21. Rowe SP, Luber B, Makell M, Brothers P, Santmyer J, Schollenberger MD et al. From validity to clinical utility: the influence of circulating tumor DNA on melanoma patient management in a real-world setting. Mol Oncol. 2018;12(10):1661-72

22. Herbreteau G, Vallee A, Knol AC, Theoleyre S, Quereux G, Varey E, et al. Quantitative monitoring of circulating tumor DNA predicts response of cutaneous metastatic melanoma to anti-PD1 immunotherapy. Oncotarget. 2018:9(38):25265-76.

23. Buchhalter I, Rempel E, Endris V, Allgauer M, Neumann O, Volckmar AL, et al. Size matters: dissecting key parameters for panel-based tumor mutational burden (TMB) analysis. Int J Cancer. 2018;144(4):848-58.

24. Eisenhauer EA, Therasse $P$, Bogaerts J, Schwartz LH, Sargent D, Ford R, et al. New response evaluation criteria in solid tumours: revised RECIST guideline (version 1.1). Eur Journal Cancer. 2009:45(2):228-47.

25. Kent WJ, Sugnet CW, Furey TS, Roskin KM, Pringle TH, Zahler AM, et al. The human genome browser at UCSC. Genome Res. 2002;12(6):996-1006.

26. Altschul SF, Madden TL, Schaffer AA, Zhang J, Zhang Z, Miller W, et al. Gapped BLAST and PSI-BLAST: a new generation of protein database search programs. Nucleic Acids Res. 1997:25(17):3389-402

27. Whale AS, Devonshire AS, Karlin-Neumann G, Regan J, Javier L, Cowen S, et al. International Interlaboratory digital PCR study demonstrating high reproducibility for the measurement of a rare sequence variant. Anal Chem. 2017;89(3):1724-33.

28. Huggett JF, Foy CA, Benes V, Emslie K, Garson JA, Haynes R, et al. The digita MIQE guidelines: minimum information for publication of quantitative digital PCR experiments. Clin Chem. 2013:59(6):892-902.

29. Chalmers ZR, Connelly CF, Fabrizio D, Gay L, Ali SM, Ennis R, et al. Analysis of 100,000 human cancer genomes reveals the landscape of tumor mutational burden. Genome Med. 2017;9(1):34. 
30. Spindler KL, Appelt AL, Pallisgaard N, Andersen RF, Brandslund I, Jakobsen A. Cell-free DNA in healthy individuals, noncancerous disease and strong prognostic value in colorectal cancer. Int J Cancer. 2014;135(12):2984-91.

31. Lyu GY, Yeh YH, Yeh YC, Wang YC. Mutation load estimation model as a predictor of the response to cancer immunotherapy. NPJ Genom Med. 2018:3:12.

32. Ashida A, Sakaizawa K, Uhara H, Okuyama R. Circulating tumour DNA for monitoring treatment response to anti-PD-1 immunotherapy in melanoma patients. Acta Derm Venereol. 2017:97(10):1212-8.

33. Zehir A, Benayed R, Shah RH, Syed A, Middha S, Kim HR, et al. Mutational landscape of metastatic cancer revealed from prospective clinical sequencing of 10,000 patients. Nat Med. 2017;23(6):703-13.

34. Hayward NK, Wilmott JS, Waddell N, Johansson PA, Field MA, Nones K, et al, Whole-genome landscapes of major melanoma subtypes. Nature. 2017; 545(7653):175-80.

35. Furney SJ, Turajlic S, Stamp G, Thomas JM, Hayes A, Strauss D, et al. The mutational burden of acral melanoma revealed by whole-genome sequencing and comparative analysis. Pigment Cell Melanoma Res. 2014; 27(5):835-8

36. Furney SJ, Turajlic S, Stamp G, Nohadani M, Carlisle A, Thomas JM, et al. Genome sequencing of mucosal melanomas reveals that they are driven by distinct mechanisms from cutaneous melanoma. J Pathol. 2013;230(3):2619 .

37. Matsushita H, Vesely MD, Koboldt DC, Rickert CG, Uppaluri R, Magrini VJ, et al. Cancer exome analysis reveals a T-cell-dependent mechanism of cancer immunoediting. Nature. 2012:482(7385):400-4.

38. Riaz N, Morris L, Havel JJ, Makarov V, Desrichard A, Chan TA. The role of neoantigens in response to immune checkpoint blockade. Int Immunol. 2016;28(8):411-9.

39. Hellmann MD, Callahan MK, Awad MM, Calvo E, Ascierto PA, Atmaca A, et al. Tumor mutational burden and efficacy of Nivolumab monotherapy and in combination with Ipilimumab in small-cell lung Cancer. Cancer Cell. 2018; 33(5):853-61 e4.

40. Morrison C, Pabla S, Conroy JM, Nesline MK, Glenn ST, Dressman D, et al. Predicting response to checkpoint inhibitors in melanoma beyond PD-L1 and mutational burden. J Immunother Cancer. 2018;6(1):32.

41. Gangadhar TC, Savitch SL, Yee SS, Xu W, Huang AC, Harmon S, et al, Feasibility of monitoring advanced melanoma patients using cell-free DNA from plasma. Pigment Cell Melanoma Res. 2018:31(1):73-81.

42. Seith F, Forschner A, Schmidt H, Pfannenberg C, Guckel B, Nikolaou K, et al. 18F-FDG-PET detects complete response to PD1-therapy in melanoma patients two weeks after therapy start. Eur J Nucl Med Mol Imaging. 2018; 45(1):95-101.

43. Conforti F, Pala L, Bagnardi V, De Pas T, Martinetti M, Viale G, et al. Cancer immunotherapy efficacy and patients' sex: a systematic review and metaanalysis. Lancet Oncol. 2018;19(6):737-46.

44. Gupta S, Artomov M, Goggins W, Daly M, Tsao H. Gender disparity and mutation burden in metastatic melanoma. J Natl Cancer Inst. 2015;107(11): djv221.

45. Xiao D, Pan H, Li F, Wu K, Zhang X, He J. Analysis of ultra-deep targeted sequencing reveals mutation burden is associated with gender and clinical outcome in lung adenocarcinoma. Oncotarget. 2016;7(16):22857-64.

46. Nosrati A, Tsai KK, Goldinger SM, Tumeh P, Grimes B, Loo K, et al. Evaluation of clinicopathological factors in PD-1 response: derivation and validation of a prediction scale for response to PD-1 monotherapy. Br J Cancer. 2017; 116(9):1141-7

47. Joseph RW, Elassaiss-Schaap J, Kefford R, Hwu WJ, Wolchok JD, Joshua AM, et al. Baseline tumor size is an independent prognostic factor for overall survival in patients with melanoma treated with Pembrolizumab. Clin Cancer Res. 2018;24(20):4960-7.

48. Shi W, Ng CKY, Lim RS, Jiang T, Kumar S, Li X, et al. Reliability of wholeexome sequencing for assessing Intratumor genetic heterogeneity. Cell Rep. 2018;25(6):1446-57.

49. Lee JHJ, Lyle M, Menzies AM, Chan MMK, Lo S, Clements A, et al. Metastasisspecific patterns of response and progression with anti-PD-1 treatment in metastatic melanoma. Pigment Cell Melanoma Res. 2018;31(3):404-10.

\section{Ready to submit your research? Choose BMC and benefit from:}

- fast, convenient online submission

- thorough peer review by experienced researchers in your field

- rapid publication on acceptance

- support for research data, including large and complex data types

- gold Open Access which fosters wider collaboration and increased citations

- maximum visibility for your research: over $100 \mathrm{M}$ website views per year

At BMC, research is always in progress.

Learn more biomedcentral.com/submissions 